Supporting Information

\title{
Induced Supramolecular Chirality in Nanostructured Materials: Ionic Self-Assembly of Perylene-chiral surfactant complexes
}

Danielle Franke, Matthijn Vos, Markus Antonietti, Nico A. J. M. Sommerdijk, Charl F. J. Faul

Includes:

- AFM analysis of complex films (Figure 1, Table 1)

- FTIR, ${ }^{1} \mathrm{H}$ NMR, UV-Vis and Fluorescence Spectra of N,N'-bis(4-benzenesulfonic acid) perylene-3,4:9,10-tetracarboxyldiimide sodium salt (1) (Figures 2-4)

- Mass and ${ }^{1} \mathrm{H}$ NMR spectra of chiral surfactant precursors, 2benzyloxycarbonylamino-6-tert-butoxycarbonylamino-hexyl hexadecanoate (1a) and 2-amino-6-tert-butoxycarbonylamino-hexyl hexadecanoate (1b) (Figures 5-8)

- UV solid-state spectra of complex films (Figure 9)

- UV and CD spectra of a mixture of $\mathbf{1}$ and 1a (Figures 10-11)

- List of citations with more than 10 authors 
For both complexes and at all investigated concentrations, a Schlieren texture was observed

(Figure 1, of complex 4 at $80 \mathrm{mg} \mathrm{mL}^{-1}$ ). The mean thickness (at the centre and edges of the films) was determined by a scratch test and, as expected, increases with increasing concentration (Table 1).

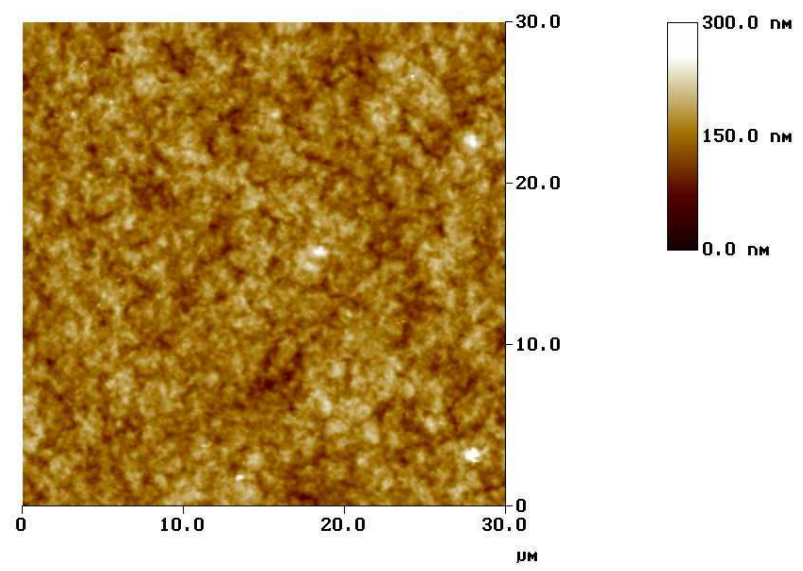

Figure 1: Tapping mode AFM topographic image of complex 4 after spin-coating from an $80 \mathrm{mg} \mathrm{mL}^{-1}$ solution in $\mathrm{CHCl}_{3}$.

\begin{tabular}{|c|c|c|}
\hline $\begin{array}{c}\text { Concentration } \\
\left(\mathrm{mg} \mathrm{mL}^{-1}\right)\end{array}$ & $\begin{array}{c}\text { Mean film thickness at center } \\
(\mathrm{nm})\end{array}$ & $\begin{array}{c}\text { Mean film thickness at edge } \\
(\mathrm{nm})\end{array}$ \\
\hline 20 & 118.5 & 59.4 \\
\hline 40 & 150.5 & 193.1 \\
\hline 60 & 231.5 & 231 \\
\hline 80 & 396.3 & 404.9 \\
\hline
\end{tabular}

Table 1. Mean thickness (at center and at edge) determined by a scratch test of films of complex 4 prepared by spin-coating from $\mathrm{CHCl}_{3}$ solutions of various concentrations. The thickness of the film is generally of a larger value at the edge than at the center. 


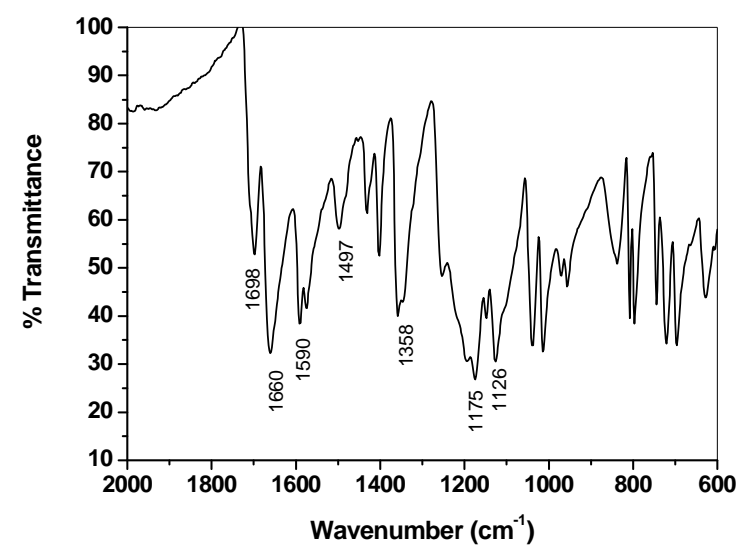

Figure 2: IR spectrum of N,N'-bis(4-benzenesulfonic acid) perylene-3,4:9,10-tetracarboxyldiimide sodium salt (1). v $C=0: 1698 \mathrm{~cm}^{-1}, 1660 \mathrm{~cm}^{-1}$; v $C=C$ (perylene core): $1590 \mathrm{~cm}^{-1}$; v $C=C$ (benzene core): $1497 \mathrm{~cm}^{-1}$; v $(O=C) N-C H: 1431 \mathrm{~cm}^{-1}$; v $(O=C)-N: 1402 \mathrm{~cm}^{-1}$; v $S_{3}^{--}: 1358 \mathrm{~cm}^{-1}, 1175 \mathrm{~cm}^{-1}, 1126 \mathrm{~cm}^{-1} ; \delta \mathrm{C}-\mathrm{H}$ (perylene core): $808 \mathrm{~cm}^{-1}, 744 \mathrm{~cm}^{-1}$.

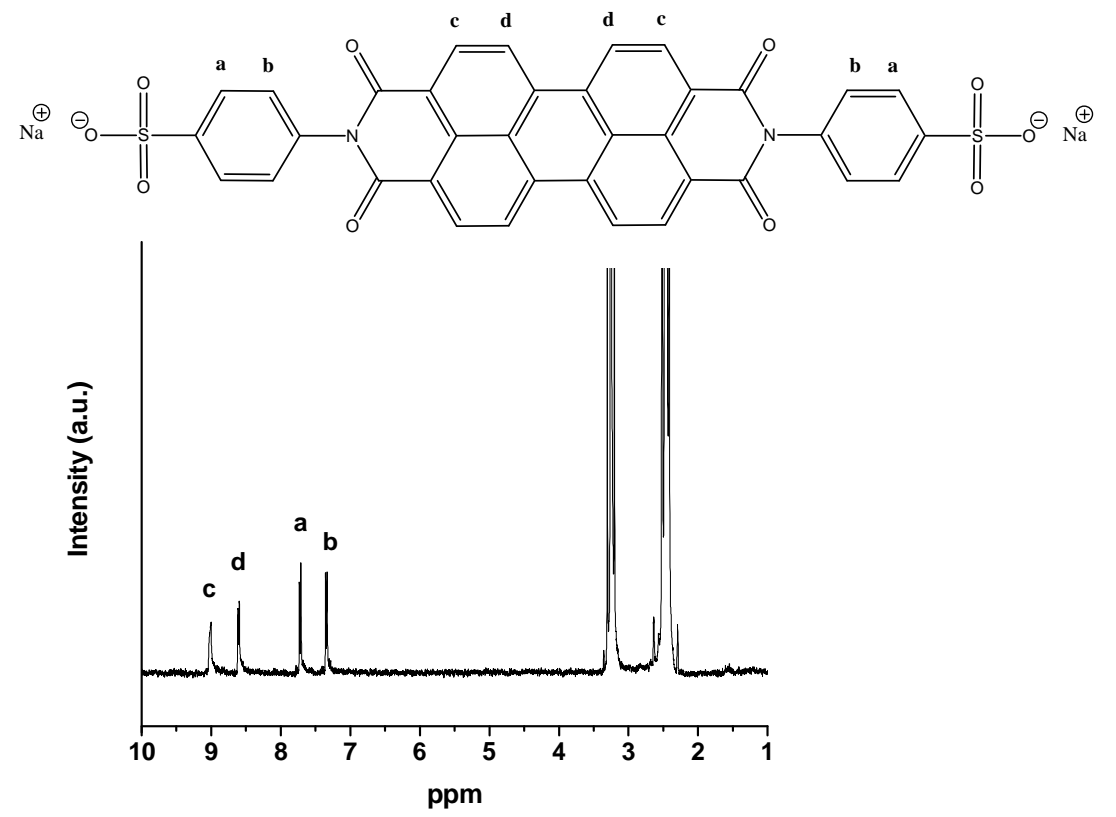

Figure 3: ${ }^{1} \mathrm{H}$ spectrum of $\mathbf{N}, \mathrm{N}^{\prime}$-bis(4-benzenesulfonic acid) perylene-3,4:9,10-tetracarboxyldiimide sodium salt (1). Solvent: DMSO-d6, $\delta 2.47$ ppm, containing $\mathrm{H}_{2} \mathrm{O}, \delta 3.31 \mathrm{ppm}$.

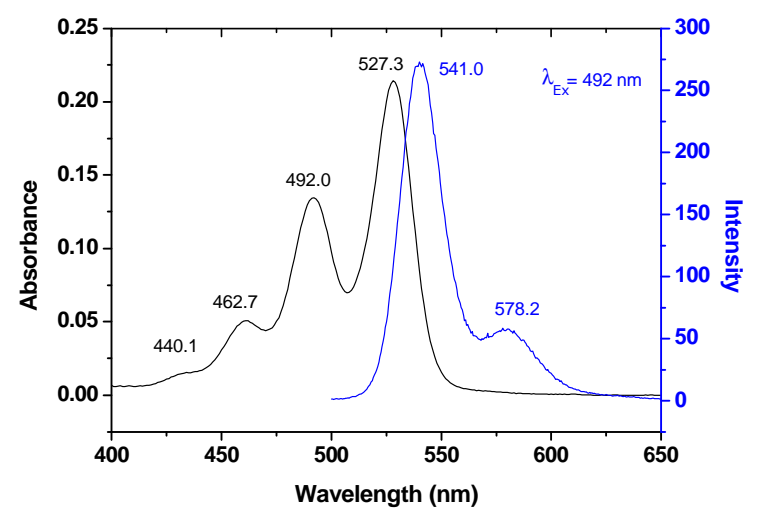

Figure 4: UV-Vis and Fluorescence spectra of N,N'-bis(4-benzenesulfonic acid) perylene-3,4:9,10tetracarboxyldiimide sodium salt (1). Solvent: DMSO; UV spectrum (black); Fluorescence spectrum (blue); excitation wavelength $=492 \mathrm{~nm}$. 


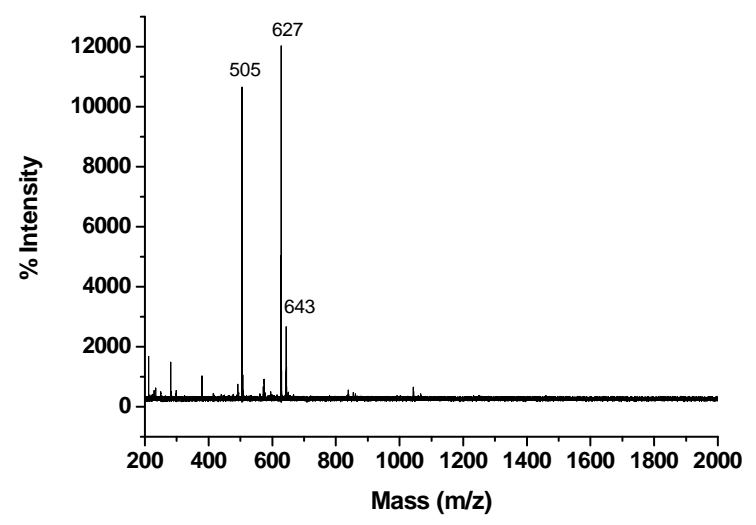

Figure 5: Mass Spectrum of 2-benzyloxycarbonylamino-6-tert-butoxycarbonylamino-hexyl hexadecanoate (1a).

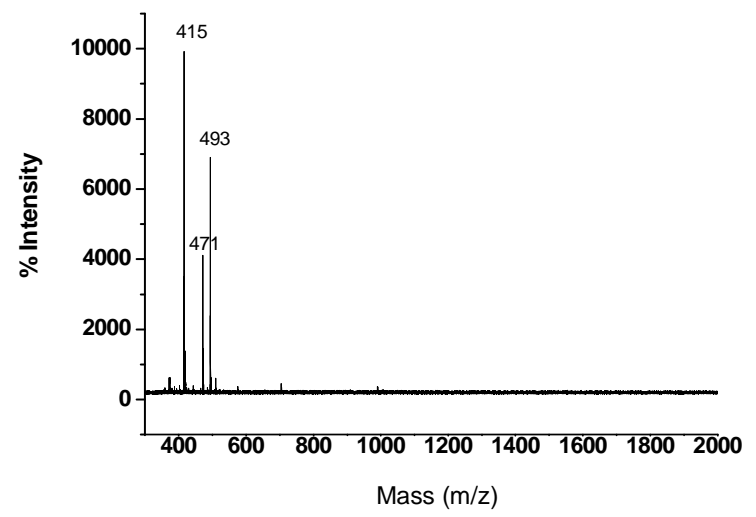

Figure 6: Mass Spectrum of 2-amino-6-tert-butoxycarbonylamino-hexyl hexadecanoate (1b).<smiles>CC(C)COC(=O)C(C)(C)NC(=O)OCc1ccccc1</smiles>

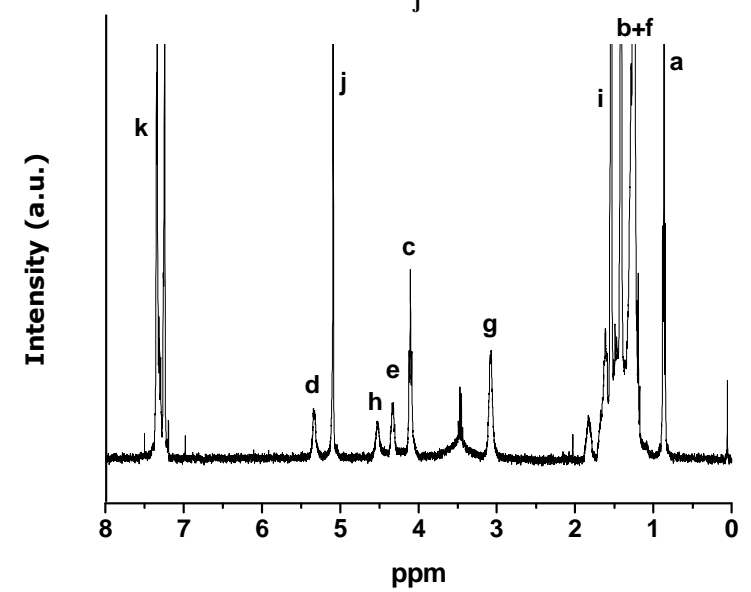

Figure 7: ${ }^{1}$ H NMR Spectrum of 2-benzyloxycarbonylamino-6-tert-butoxycarbonylamino-hexyl hexadecanoate (1a). 

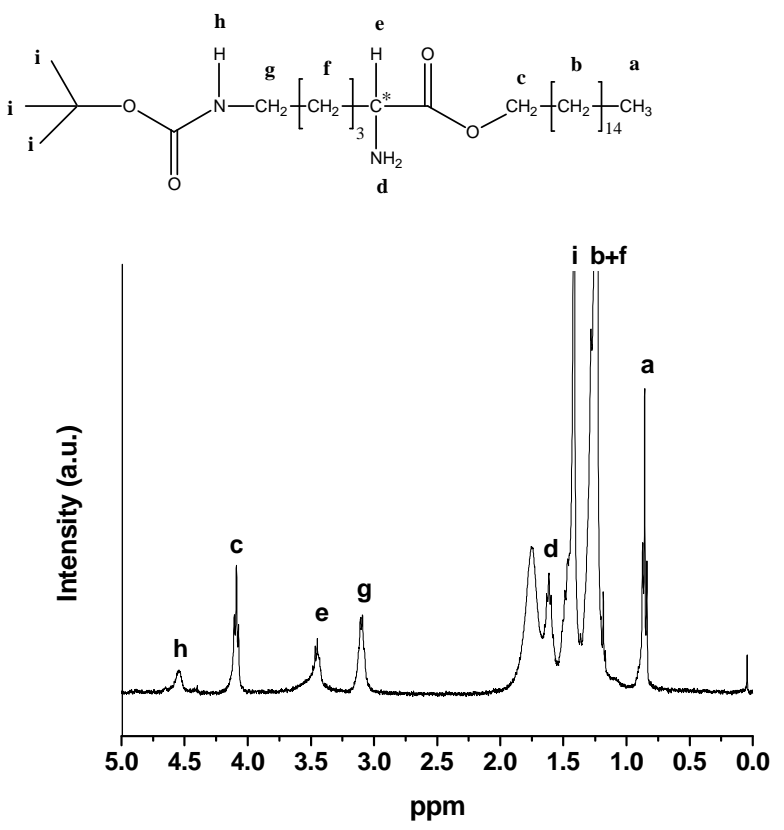

Figure 8: ${ }^{1} \mathrm{H}$ NMR Spectrum of 2-amino-6-tert-butoxycarbonylamino-hexyl hexadecanoate (1b).

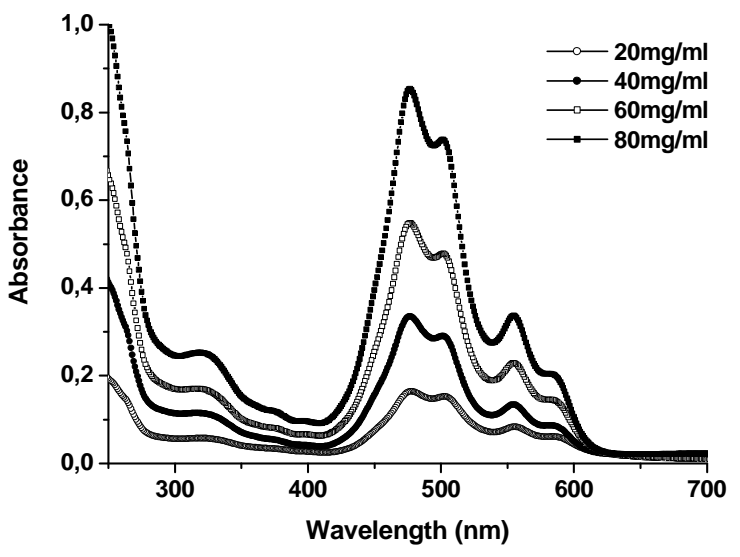

Figure 9: Solid-state UV-VIS spectra of complex 5, as thin films spin-coated from $\mathrm{CHCl}_{3}$ solutions of varying concentrations $\left(20,40,60\right.$ and $\left.80 \mathrm{mg} \mathrm{mL}^{-1}\right)$. The spectra do not show changes in the optical properties upon concentration variation, at least within the range of concentration measured. 


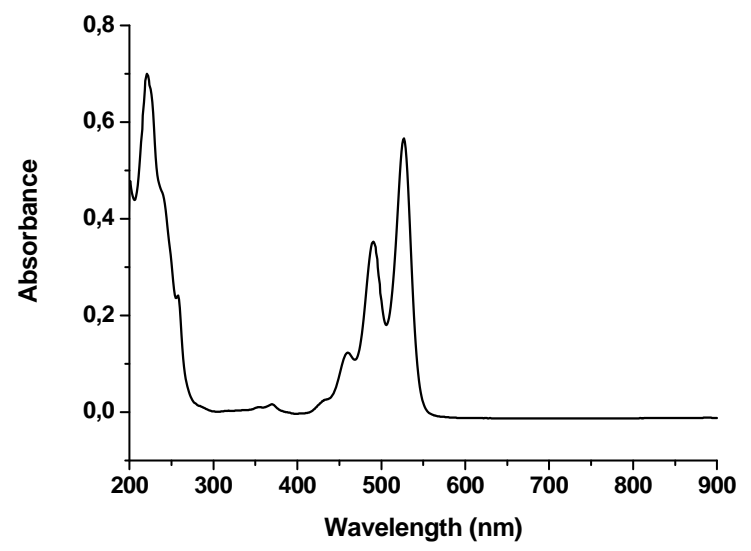

Figure 10: UV-VIS spectrum of a mixture of $\mathrm{N}, \mathrm{N}$ '-bis(4-benzenesulfonic acid) perylene-3,4:9,10tetracarboxyldiimide sodium salt (1) and 2-benzyloxycarbonylamino-6-tert-butoxycarbonylamino-hexyl hexadecanoate (1a) in THF: $\mathrm{H}_{2} \mathrm{O}(1: 1)$ solution. The concentration of both 1 and 1 a was $0.05 \mathrm{mg} \mathrm{mL}^{-1}$.

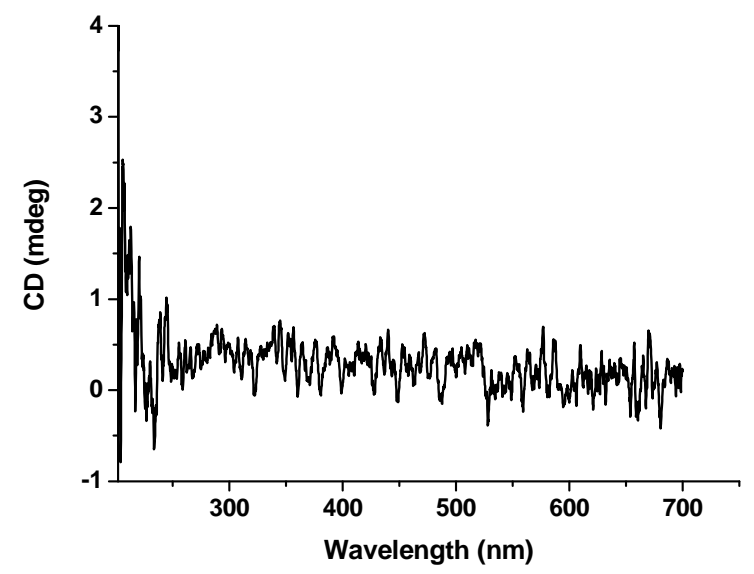

Figure 11: CD spectrum of a mixture of N,N'-bis(4-benzenesulfonic acid) perylene-3,4:9,10tetracarboxyldiimide sodium salt (1) and 2-benzyloxycarbonylamino-6-tert-butoxycarbonylamino-hexyl hexadecanoate (1a) in THF: $\mathrm{H}_{2} \mathrm{O}(1: 1)$ solution. The concentration of both 1 and $1 \mathrm{a}$ was $0.05 \mathrm{mg} \mathrm{mL}^{-1}$. The spectrum shows a cotton effect only in the absorption range of the chiral surfactant. The absence of a cotton effect in the perylene absorption range implies that the induced chiral effect only occurs on complexation of the dye with the chiral surfactants.

List of citiations with more than 10 authors:

1) Fernandez-Lopez S.; Kim H.-S.; Choi E. C.; Delgado M.; Granja J. R.; Khasanov A.; Kraehenbuehl K.; Long G.; Weinberger D. A.; Wilcoxen K. M.; Ghadiri M. R. Nature $2001,412,452-455$. 
2) Struijk C. W.; Sieval A. B.; Dakhorst J. E.; van Dijk M.; Kimkes P.; Koehorst R. B. M.; Donker H.; Schaafsma T. J.; Picken S. J.; van de Craats A. M.; Warman J. M.; Zuilhof H.; Sudhölter E. J. R. J. Am. Chem. Soc. 2000, 122, 11057-11066.

3) Würthner F.; Chen Z.; Hoeben F. J. M.; Osswald P.; You C.-C.; Jonkheijm P.; v. Herrikhuyzen J.; Schenning A. P. H. J.; van der Schoot P. P. A. M.; Meijer E. W.; Beckers E. H. A.; Meskers S. C. J.; Janssen R. A. J. J. Am. Chem. Soc. 2004, 126, 10611-10618. 